\title{
The development and validation of sensory and emotional scales of touch perception
}

\author{
Steve Guest • Jean Marc Dessirier • Anahit Mehrabyan • Francis McGlone • \\ Greg Essick • George Gescheider • Anne Fontana • Rui Xiong • Rochelle Ackerley • \\ Kevin Blot
}

Published online: 9 November 2010

(C) Psychonomic Society, Inc. 2010

\begin{abstract}
No comprehensive language exists that describes the experience of touch. Three experiments were conducted to take steps toward establishing a touch lexicon. In Experiment I, 49 participants rated how well 262 adjectives described sensory, emotional and evaluative aspects of touch. In Experiment II, participants rated pairwise dissimilarities of the most descriptive words of the set. Multidimensional scaling (MDS) solutions representing semanticperceptual spaces underlying the words resulted in a touch
\end{abstract}

S. Guest · A. Mehrabyan · G. Essick

Center for Neurosensory Disorders, School of Dentistry,

University of North Carolina,

Chapel Hill, NC, USA

J. M. Dessirier $\cdot$ R. Xiong $\cdot$ K. Blot $(\square)$

Sensation, Perception \& Behavior, Unilever R\&D,

40 Merritt Blvd,

Trumbull, CT, USA

e-mail: kevin.blot@unilever.com

F. McGlone $\cdot$ R. Ackerley

School of Natural Sciences \& Psychology,

Liverpool John Moores University,

Liverpool, UK

G. Gescheider

Institute for Sensory Research, Syracuse University,

Syracuse, NY, USA

\section{A. Fontana}

Behavioral Measurements, Inc,

Cazenovia, NY, USA

R. Ackerley

Institute of Neuroscience and Physiology,

University of Gothenburg,

Gothenburg, Sweden

R. Ackerley

Sahlgrenska University Hospital,

Gothenburg, Sweden perception task (TPT) consisting of 26 'sensory' attributes (e.g., bumpiness) and 14 'emotional' attributes (e.g., pleasurable). In Experiment III, 40 participants used the TPT to rate unseen textured materials that were moved actively or received passively against the index fingerpad, volar forearm, and two underarm sites. MDS confirmed similar semantic-perceptual structures in Experiments II and III. Factor analysis of Experiment III data decomposed the sensory attribute ratings into factors labeled Roughness, Slip, Pile and Firmness, and the emotional attribute ratings into Comfort and Arousal factors. Factor scores varied among materials and sites. Greater intensity of sensory and emotional responses were reported when participants passively, as opposed to actively, received stimuli. The sensitivity of the TPT in identifying body site and mode of touch-related perceptual differences affirms the validity and utility of this novel linguistic/perceptual tool.

Keywords Touch $\cdot$ Texture perception $\cdot$ Psychometric testing $\cdot$ Factor analysis $\cdot$ Multidimensional scaling

\section{Introduction}

The value of having an accurate, reliable language (or lexicon) to describe perceptual experiences is clear (Bhushan, Rao, \& Lohse, 1997; Osgood, 1952; Stevenson \& Boakes, 2003). Although lists of the actions applicable to tactile and haptic exploration exist (Lederman \& Klatzky, 1987, 1990), no descriptive scheme is available yet for the sense of touch. Our major objective is to take the first steps to develop such a lexicon for touch.

Effort has been directed toward a related problem, namely, determining what (orthogonal) perceptual dimensions form the basis of our interactions with texture. Following an approach originated by Yoshida (1968), 
multidimensional scaling (MDS) techniques revealed that a primary dimension of touch perception is RoughSmoothness (Bergmann Tiest \& Kappers, 2006; Hollins, Bensmaïa, Karlof, \& Young, 2000; Hollins, Faldowski, Rao, \& Young, 1993; Na \& Kim, 2001; Picard, Dacremont, Valentin, \& Giboreau, 2003). The enduring popularity of roughness as a psychophysical measure is consistent with this finding (Gescheider, Bolanowski, Greenfield, \& Brunette, 2005; Klatzky \& Lederman, 1999; Lederman, 1974; Lederman \& Taylor, 1972; Major, 1895; Ripin \& Lazarsfeld, 1937; Smith, Chapman, Deslandes, Langlais, \& Thibodeau, 2002). A Hard-Soft dimension has also been identified, which is consistent with the finding that 'softness' is also an important tactile attribute (LaMotte, 2000; Srinivasan \& LaMotte, 1995). The interpretation of a tertiary dimension has been less clear. The label Springiness (e.g., elastic resilience) has been suggested (Hollins et al., 1993), as has StickySlipperiness, but considerable variation is evident between participants (Hollins et al., 2000). Interpretation of the results of these research studies is complicated by the different native languages of participants (cf. Picard et al., 2003), by the higher-order solution dimensionality chosen as most appropriate by some researchers (e.g., the four-dimensional solution of Bergmann Tiest \& Kappers, 2006), by different experimenter's idiosyncratic choices of stimulus materials and by the subjective nature of labeling solution dimensions.

Although there is some consensus regarding what perceptual dimensions a touch lexicon should describe, many questions remain. For example, while lexical descriptors necessarily map into a perceptual space, it is unclear what specific descriptors are consistently used to describe the underlying dimensions of touch. It is also unknown whether such descriptors are scattered throughout perceptual space or instead whether certain regions of tactile perceptual space are poorly sampled by the natural language applicable to touch. Additionally, the role of emotional attributes in touch perception remains open to question. Little is known in this regard beyond the observation that 'pleasantness' and allied percepts are important (for 'comfort', see Cardello, Winterhalter, \& Schutz, 2003; Essick, James, \& McGlone, 1999; Essick et al., 2010; Guest et al., 2009; Major, 1895; Picard et al., 2003; Ripin \& Lazarsfeld, 1937). For example, it is unclear how many emotional dimensions exist with respect to tactile perceptual space, and whether such emotional dimensions are related to the established sensory dimensions.

Here, we report a series of experiments that provide initial steps toward developing a lexicon for touch, following the methodology used by Melzack (1975) in the development of the McGill Pain Questionnaire (see also Bhushan et al., 1997; Petiot \& Yannou, 2004; Zhang,
Helander, \& Drury, 1996). In a first experiment, candidate words for a touch lexicon were compiled. In a second experiment, MDS was used to characterize these words in terms of their location in a perceptual space, which allowed further refinement of the candidate lexicon. In a third experiment, a touch perception task (TPT) was created from the refined candidate words. The TPT was used to investigate the perception of textured stimuli applied to sites on the upper limb to ascertain its effectiveness in uncovering perceptual differences as a function of whether the participant or experimenter applied the stimuli (i.e., intra- versus interpersonal touch; see Guest et al., 2009) and the specific body site over which the texture moved (Essick et al., 1999, 2010).

\section{Experiment I: identifying emotional and sensory words describing the experience of touch}

The objective of Experiment I was to generate a succinct list of the most commonly used adjectives in the English language to describe touch experience, and to determine how strongly different aspects of the touch experience (i.e., sensory, emotional and evaluative; see Melzack, 1975) were represented by these words.

\section{Methods}

\section{Participants}

Forty-nine female undergraduates (age range 18-24 years, mean 19.7 years) from three colleges in the Eastern United States volunteered to participate in the study and provided informed consent. Ninety percent of the participants described themselves as Caucasian, $4 \%$ as African American, $4 \%$ as Hispanic and $2 \%$ as Asian.

\section{Design and procedure}

Participants were given a booklet containing 262 adjectives (Table 1) describing different aspects of the sense of touch that was generated by reviewing the scientific literature on tactile perception (e.g., Lederman \& Klatzky, 1987, 1990) and using standard linguistic reference tools (e.g., dictionary, encyclopedia, thesaurus). The adjective 'vibrating' appeared twice in the booklet to provide a means of checking rating reliability. Participants were asked to rate the extent to which each word referred to sensory, emotional, and evaluative (after Melzack, 1975) aspects of touch. Definitions were provided, as follows: 'Sensory' referred to the pure sensations resulting from the act of touching or being touched. 'Emotional' referred to the 
feelings that occur when touching or being touched. 'Evaluative' referred to the overall significance and importance of the touch experience. Examples of words in Table 1 that were expected to be evaluative, but not strongly sensory or emotional, are 'significant' and 'impacting'. The participant rated, on a 4-point scale, the extent to which each word referred to each of these aspects of touch. The scale values were: 1, "Has nothing to do with this aspect of touch"; 2, "Refers slightly to this aspect of touch"; 3, "Refers moderately to this aspect of touch"; and 4, "Refers strongly to this aspect of touch". All three aspects of touch were rated for each word before moving on to the next.

\section{Statistical analysis ${ }^{1}$}

Histograms were generated for each of the 262 words that showed separately the rating frequencies for each aspect of touch (sensory, emotional and evaluative). To provide an initial culling, a word was excluded from further analysis if its modal rating was less than 3 (i.e., "Refers moderately to this aspect of touch") for all three aspects of touch.

To further refine the set of words, those retained after the initial culling were ranked on the basis of their ratings, for each participant, via two different schemes. In each scheme, the ranking was arranged such that lower ranks represented more applicable aspects of touch. The first scheme ("within aspect") ranked all the words within each of the three aspects of touch, resulting in three orderings for each participant. That is, one ordering consisted of the words ranked on the basis of their sensory ratings, a second ordering ranked the words on the basis of their emotional ratings, and a third ranked the words on the basis of their evaluative ratings.

The second scheme ("within word") ordered the aspects of touch for each individual word, resulting in one ordering per word for each participant. That is, the sensory, emotional and evaluative ratings made for each word were inspected, and the aspect of touch that received the largest rating was ranked in first position, whereas the aspect of touch that received the smallest rating was ranked in last (i.e., third) position. Mean ranks were subsequently calculated among all participants for both ranking schemes. The means were then inspected to permit a second stage of word selection.

\footnotetext{
${ }^{1}$ Initially, we analyzed the psychophysical ratings using conventional parametric statistics, i.e., means of ratings. One of the anonymous reviewers suggested that the four-level nature of the ratings necessitated a non-parametric approach, and such an approach is now reported.
}

\section{Results and discussion}

Initial culling reduced the original set of 262 words to 168 , all of which referred to a 'moderately' or 'strongly' descriptive of at least one aspect of touch. A detailed breakdown of the aspects of touch and the corresponding frequency of words that met the modal criterion are shown in Table 2. The Table illustrates that many words (124) were descriptive of sensory aspects of touch, and simultaneously not descriptive of emotional or evaluative aspects. Fewer words met the criterion for emotional, and a high proportion of these words also met the criterion for evaluative. However, such words were invariably ranked as less evaluative than emotional. Furthermore, evaluative words were usually additionally descriptive of sensory and/ or emotional aspects of touch, and were ranked as less evaluative than they were sensory or emotional. On this basis, the evaluative category was not included for further study.

Table 2 also shows that no words were considered moderately or strongly descriptive of both sensory and emotional aspects of touch. That is, participants identified words as predominately belonging to the sensory or the emotional category, with minimal overlap between the two categories. As a result, in subsequent experiments analyses were conducted separately for emotional and sensory attributes.

To further reduce the candidate set of words, scatterplots were produced showing the mean within word ranks against the mean within aspect ranks for words that passed the initial selection for sensory (Fig. 1a) and emotional aspects of touch (Fig. 1b). All the sensory words passing the initial selection are shown in the small inset figure at the bottom left of Fig. 1a. The main region of Fig. 1a provides a closer look at the 66 words which lay in the shaded box of the inset figure. The shaded box includes words which lay in the top half of the mean sensory ranks for the within aspect ranking ( $\leq 75$, abscissa), and less than or equal to 1.5 for the within word ranking (ordinate). The words within this region provide a candidate lexicon for the sensory category of touch. Note that vibrating appears twice in the plot (the points are linked by a dotted line in Fig. 1a), corresponding to the two appearances of vibrating in the initial list of words. The close proximity of the two points indicates good reliability in the assessment of the term with respect to the sensory aspect of touch.

Fewer words passed the initial selection for the emotional aspect of touch than the sensory aspect, and all such words are shown in Fig. 1b. These 31 words, without further reduction via the ranking criteria, provide a candidate lexicon for the emotional aspect of touch.

The complete set of 97 sensory and emotional words was considered too large to be practicable for further investigation 
Table 1262 candidate words for a touch lexicon

\begin{tabular}{|c|c|c|c|c|c|}
\hline Abrasive & Decisive & Gelatinous & Meaty & Rugged & Taut \\
\hline Achy & Dehydrated & Gentle & Moist & Sandy & Tender \\
\hline Airy & Delicate & Glassy & Mushy & Satiny & Tense \\
\hline Annoying & Demanding & Glossy & Nappy & Scabby & Tension \\
\hline Arctic & Dense & Gooey & Nice & Scalding & Tepid \\
\hline Arid & Desirable & Goopy & Nippy & Scaly & Textured \\
\hline Arousing & Determined & Grainy & Notable & Scorching & Thick \\
\hline Attending & Diffuse & Granular & Noticeable & Scraping & Thorny \\
\hline Aversive & Dirty & Grating & Oily & Scratchy & Thrilling \\
\hline Blissful & Discomfort & Greasy & Oozy & Searing & Tickling \\
\hline Blunt & Distinctive & Grimy & Overheated & Sensual & Ticklish \\
\hline Breezy & Distressing & Gritty & Painful & Sexy & Tickly \\
\hline Bristly & Doughy & Grooved & Parched & Shaggy & Tight \\
\hline Brittle & Downy & Gummy & Pat & Shallow & Tortuous \\
\hline Bumpy & Drenched & Hairy & Pebbly & Sharp & Tough \\
\hline Burning & Dry & Hard & Persistent & Significant & Tranquil \\
\hline Bushy & Dull & Heavenly & Pert & Silky & Transient \\
\hline Callous & Effervescent & Horny & Placid & Sinuous & Translucent \\
\hline Calming & Elastic & Hot & Plastic & Slack & Trim \\
\hline Chafed & Enjoyable & Hydrous & Pleasurable & Slick & Uneven \\
\hline Chalky & Erotic & Icky & Pliable & Slimy & Unyielding \\
\hline Chapped & Evocative & Icy & Plush & Slippery & Vague \\
\hline Chilly & Exciting & Impacting & Pointed & Sludgy & Velvety \\
\hline Clammy & Feathery & Important & Pointy & Slushy & Veneered \\
\hline Clean & Filmy & Indented & Poked & Smear & Vibrating \\
\hline Clear & Fine & Inflexible & Polished & Smooth & Viny \\
\hline Coarse & Firm & Intense & Porous & Soapy & Viscous \\
\hline Cold & Flabby & Irregular & Pounding & Soft & Vivid \\
\hline Comfortable & Fleecy & Irritable & Powdery & Solid & Warm \\
\hline Compliant & Fleeting & Irritating & Pressed & Soothing & Watery \\
\hline Compressed & Fleshy & Itchy & Pressure & Spiky & Waxy \\
\hline Consequential & Flexible & Jagged & Prickly & Spiny & Weird \\
\hline Contact & Florid & Leathery & Provocative & Spongy & Wet \\
\hline Cool & Fluffy & Light & Pulpy & Springy & Wiggly \\
\hline Cottony & Fluttering & Liquidly & Purposeful & Squeezed & Woodsy \\
\hline Crawling & Focused & Lively & Raw & Squishy & Woody \\
\hline Creamy & Fragile & Localized & Relaxing & Steely & Wooly \\
\hline Creepy & Freezing & Lumpy & Resolute & Sticky & Worn \\
\hline Crispy & Friction & Luscious & Ribbed & Stringy & Wrinkly \\
\hline Crumbly & Frigid & Lush & Rigid & Supple & Yielding \\
\hline Crusty & Frosty & Malleable & Rippley & Sweaty & Yucky \\
\hline Cushy & Furry & Matted & Robust & Sweeping & Yummy \\
\hline Damp & Fuzzy & Mealy & Rough & Tactual & \\
\hline Deadened & Gauzy & Meaningful & Rubbery & Tap & \\
\hline
\end{tabular}

in Experiment II (see Melzack, 1987 for a similar issue regarding the MPQ). Therefore, a subset of the candidate words shown in Fig. 1 was selected. To perform the selection, where synonyms were present according to standard dictionary definitions, only one of such terms was retained (e.g., scalding and burning; burning was retained).
Further, the words retained were those that, on consideration, appeared general in their applicability rather than being limited in scope to specific surfaces. For example, furry was excluded while, in contrast, fuzzy, coarse and prickly were retained as such words were considered likely to refer to surface properties rather than an entire surface per se. The set 
Table 2 Distribution of 168 words selected as moderately or strongly descriptive of three aspects of touch (sensory, emotional, evaluative). Note that the table is symmetrical around its major diagonal. Intersections of columns and rows in the table indicate words that were selected as describing both of those aspects listed at the head of the respective column and row. For example, 5 words were selected as descriptive of both sensory and evaluative aspects of touch
Aspect of touch

\begin{tabular}{lll}
\hline Sensory & Emotional & Evaluative \\
\hline 124 & 0 & 5 \\
0 & 12 & 13 \\
5 & 13 & 8 \\
6 & &
\end{tabular}

of candidate emotional words was reduced similarly. In this latter case, the reduction required fewer judgments to be made regarding which words to exclude, given the smaller size of the candidate emotional word set. After this process, 33 sensory words and 16 emotional words were retained (those circled in Fig. 1). Although these words are strongly referential of the experience of touch, the results of Experiment I in isolation do not allow one to ascertain the way the words relate to each other in terms of their locations in an underlying semantic-perceptual space. Determining the locations of the words in such a perceptual space was the purpose of Experiment II.

\section{Experiment II: identifying sensory and emotional dimensions of touch}

In Experiment II, the objective was to identify, using MDS, the dimensions of the semantic-perceptual space underlying the emotional and sensory words generated in Experiment I. By knowing the number and nature of the dimensions, one can determine which words are required to sample the entire space. Using solely the terms in a lexicon, it should be possible to describe any relevant tactile experience. Thus, words should be sampled from all regions of the space, i.e., along all major axes. Additionally, comparison of MDS solutions obtained from data representing perceptions of physical stimuli (in prior studies, Bergmann et al., 2006; Hollins et al., 1993, 2000; Na \& Kim, 2001; Picard et al., 2003) versus perceptions of adjectives (in Experiment II) provides a measure of structural similarity between physically- and semantically-based touch spaces.

\section{Methods}

Participants

Sixty-eight female undergraduates volunteered to participate. Thirty-five of these individuals (age range 18-24 years, mean
20.1 years) took part in a subset of the experiment dedicated to 33 sensory words only, while the remaining 33 (age range 1823 years, mean 20.0 years) took part in a subset dedicated to 16 emotional words only. Of the 68 participants, $81 \%$ selfidentified as Caucasian, with the remaining 19\% identifying as Asian, Hispanic and African American with similar probability.

\section{Design \& procedure}

Participants were asked to rate all possible paired combinations of the 33 sensory or 16 emotional words derived from Experiment I on a 15-point scale of dissimilarity, with 1 being "no difference in meaning" and 15 being the "most different in meaning." The participant was asked to base her judgments on her own opinions of how each word in the pair is used in the English language. The order of presentation of the word pairs was randomized. This procedure was performed separately for the emotional and sensory words.

\section{Statistical analysis}

MDS (SPSS's ALSCAL procedure) was used to organize participants' dissimilarity ratings into a perceptual space so that the difference in meaning between any two words reflected their perceptual distinctiveness. To determine the appropriate solution dimensionality for the MDS data, S-stress plots were used. Specifically, the dimensionality at which a sharp 'elbow' was seen in the stress versus dimensionality curve indicated the appropriate choice of solution dimensionality (Cattell, 1978).

\section{Results and discussion}

\section{Sensory attributes}

Figure $2 \mathrm{a}$ shows the S-stress plot for the analysis of sensory attribute dissimilarity values, indicating a slight change in slope at three dimensions (squared reliability 
Fig. 1 Mean rankings of words in terms of their $\mathbf{a}$ sensory or $\mathbf{b}$ emotional ratings. Within-aspect rankings are shown along the abscissa, within-word.rankings along the ordinate. Inset in a shows the complete set of words which were considered descriptive of the sensory aspect of touch. The main figure shows the set of words from the shaded rectangle within the inset. Encircled datapoints in $\mathbf{a}$ and $\mathbf{b}$ denote words that were selected for further consideration in Experiment II. More details regarding their selection is given in the main text

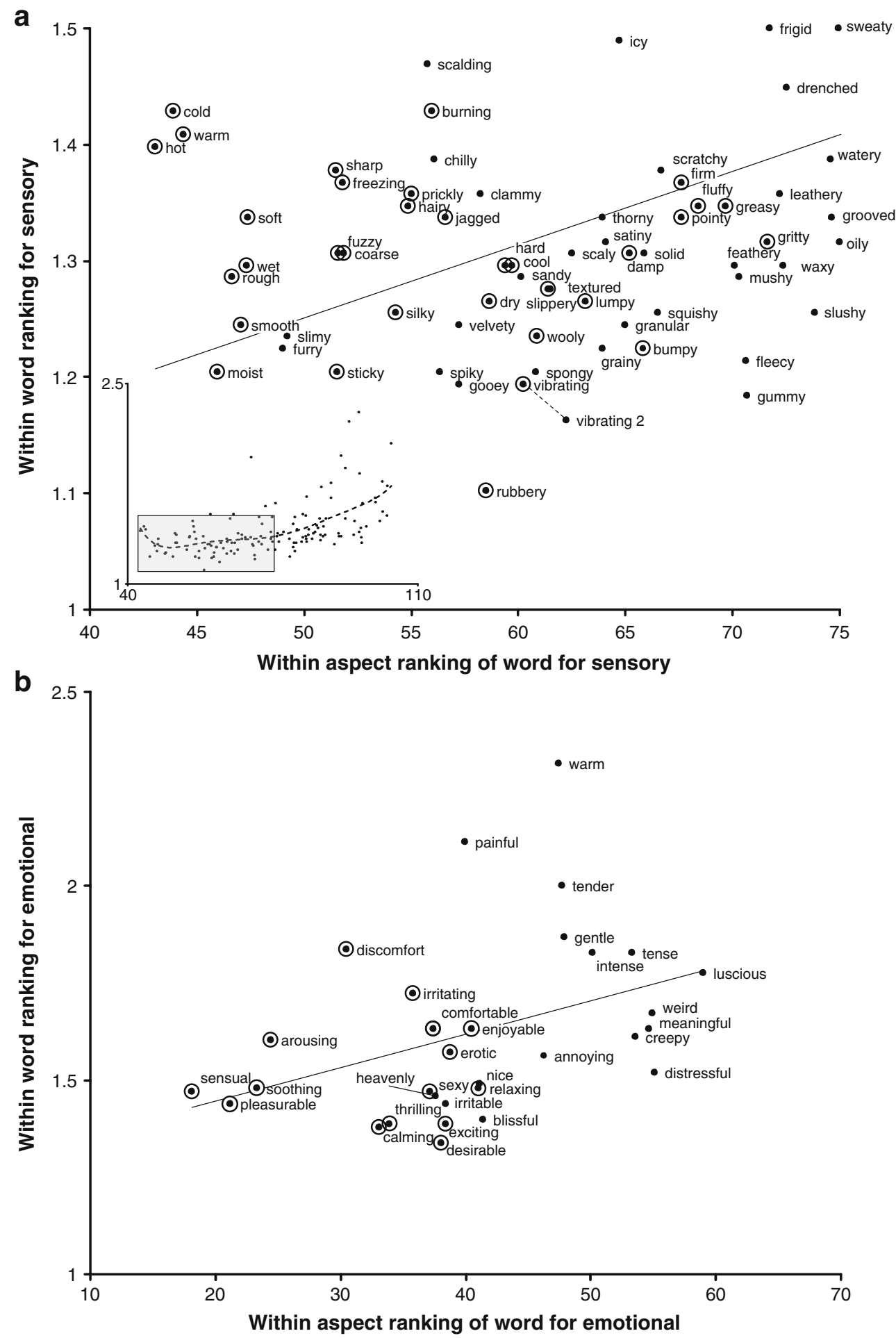

coefficient $=.24$; stress $=.18$ ). A four-dimensional solution was also considered, but dismissed on the basis that the fourth dimension appeared to be relatively limited in the attributes it discriminated among, essentially separating vibrating and rubbery from bumpy and lumpy, with the majority of remaining attributes very closely grouped. Thus, the three dimensional solution was accepted.
An examination of the plot of dimension scores for the different attributes (Fig. 2b) suggests clearly the characteristics of the different dimensions: Dimension 1 represents Smooth versus Rough; Dimension 2, Dry versus Wet; Dimension 3, Hot versus Cold. Although the dimensions identified do not include one specific to softness, a soft versus hard axis would result from a small clockwise 


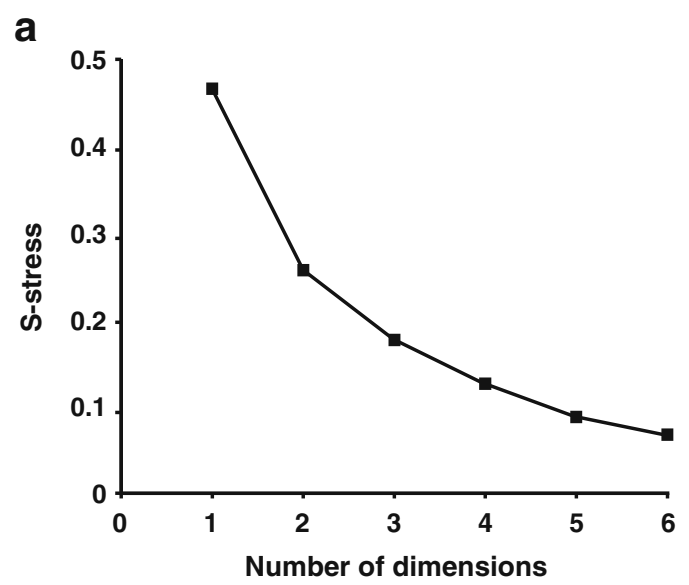

b
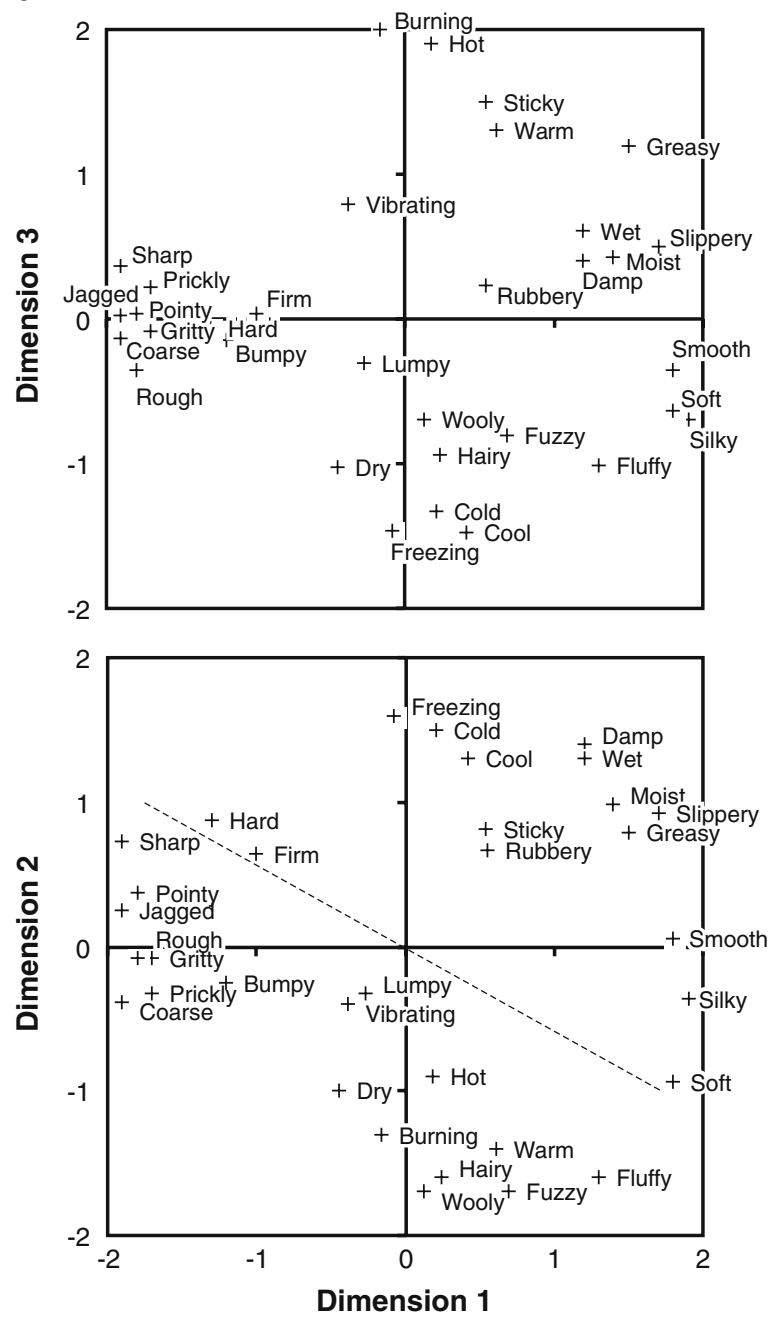

Fig. 2 a S-stress plot for MDS solutions for sensory attributes. b MDS solution for sensory attributes. The dotted line represents the possible orientation of a soft versus hard dimension within the space

rotation of the first and second axes (see dotted line in Fig. 2b). However, although a soft-hard axis could be created in this way, the solution suggests that smoothness (roughness) and softness (hardness) are not orthogonal in the semantic-perceptual space. A similar finding has been reported from an experiment that used an extensive collection of actual physical materials (Bergmann et al., 2006). The authors suggested that the non-orthogonality of smoothness and softness axes could be because these perceptual attributes tend to be correlated in physical materials. That the semantic-perceptual space of Experiment II reveals a similar structure to the perceptual space, obtained by assessment of actual material stimuli, indicates that the language that may be used to describe the experience of touch maps well to the physical experience of touch.
Emotional attributes

As seen in Fig. 3a, there was a clear 'elbow' identified in the S-stress plot at three dimensions, after which point goodness of fit improved very little. Therefore, we chose to represent the multidimensional space of the emotional words in three dimensions. This provided an optimal fit to the data (squared reliability coefficient $=.98$; stress $=.06$ ).

An examination of the MDS solution plot (Fig. 3b) clearly indicates that Dimension 1 represents Discomfort versus Comfort, and Dimension 2 low versus high Arousal. Dimension 3 appears to describe different qualities of sensual experience, ranging from those that may be considered stimulating and sensual, to those conveying more general, somatic meaning. It is difficult to arrive at a simple label for Dimension 3, although a phrase such as 

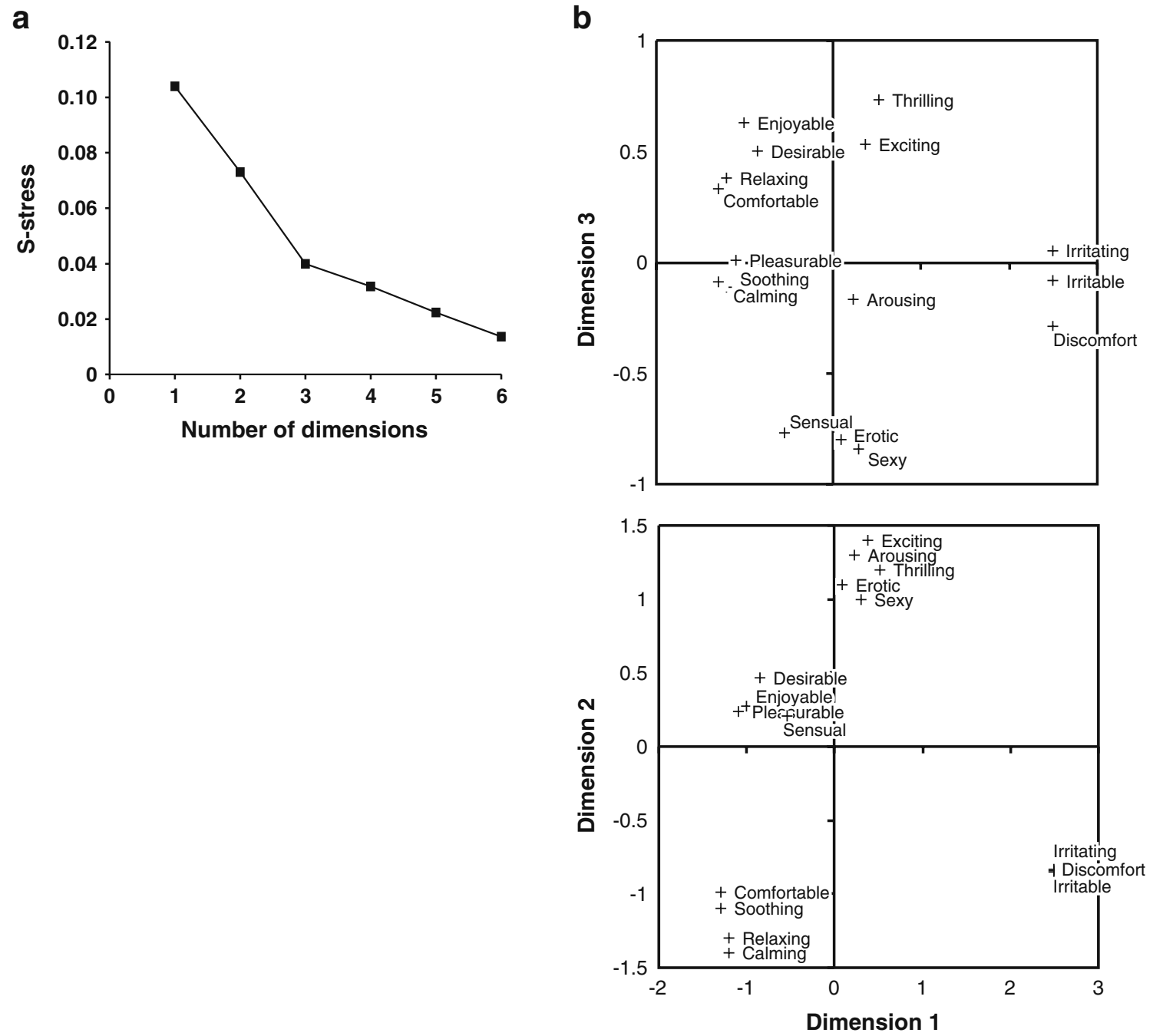

Fig. 3 a S-stress plot for MDS solutions for emotional attributes. b MDS solution for emotional attributes

Sensual Quality conveys much of what is described by the dimension. An interesting observation is that the high Arousal words (e.g., thrilling, sexy) had a relatively neutral emotional meaning with regard to the Comfort dimension (as indicated in the Dimension 2-Dimension 1 plot of Fig. 3), with these words falling toward the middle of the Dimension 1 scale).

The positions of the words in the MDS space provide a measure of convergent and discriminant validity, as follows. Convergent validity is supported because the words that have similar meanings in English were spatially close in the MDS solution. Discriminant validity is supported in that words with unrelated meanings in English were essentially randomly spaced with respect to each other in the MDS solution. The grouping of words allowed for a final, shorter candidate lexicon, which was obtained from the 49 words used in Experiment II by eliminating one word of a pair that appeared to be synonyms, as indicated by their scale score patterns. The word of the pair to be retained was selected on the basis of its frequency of use in English (British National Corpus, 2007). The final terms of the candidate lexicon consist of those circled in Fig. 1, minus coarse, cool, freezing, moist, pointy, silky and wooly from the sensory attributes and irritable and sexy from the emotional attributes, leaving 26 sensory and 14 emotional attributes. Notably, most terms were retained to permit measurement of nuances of meaning as well as the potential to derive linear combinations of attributes to form stable subscales of the underlying dimensions in applications. Experiment III serves as a test of the shorter set of words, ascertaining their effectiveness in assessing actual stimuli.

\section{Experiment III: tactile perception on the upper limb}

Experiments I and II identified a set of sensory and emotional attributes that cover the salient dimensions of texture perception space. However, the attributes that 
comprise the set were not derived with reference to actual stimulus materials, but rather with reference to words only. It is important to test empirically use of the words in describing physical stimuli. For example, only subsets of the words might be used to describe physical stimuli, suggesting that further reduction in the number of terms is indicated. A suitable lexicon should be able to represent any set of physical stimuli such that all relevant perceptual dimensions that describe that set are present. Thus, in Experiment III, we obtained ratings of the words in response to textured materials moved over several sites on the upper limb. This allowed us to investigate how the set of candidate words are used in representing the perception of specific textured materials, as opposed to considering what the words are that might be used to describe touch perception in a general sense (i.e., Experiments I and II).

Different body sites vary in tactile perception, with clear sitewise differences in sensory and affective responses. For example, the finger is very adept at discriminating fine textural differences (Sathian \& Zangaladze, 1996). In contrast, the forearm is less sensitive in this regard, but stimulation can evoke a large affective response (Essick et al., 2010; Guest et al., 2009; Löken, Wessberg, Morrison, McGlone, \& Olausson, 2009). Hairy skin, such as that of the forearm, is innervated by low-threshold C-tactile (CT) mechanoreceptors that are important in conveying affective touch (Liu et al., 2007; Löken, et al., 2009; McGlone, Vallbo, Olausson, Loken, \& Wessberg, 2007; Vallbo, Olausson, \& Wessberg, 1999; Vallbo, Olausson, Wessberg, \& Norrsell, 1993; Wessberg, Olausson, Fernström, \& Vallbo, 2003). In contrast, glabrous skin (e.g., of the fingerpad) lacks CT afferents (Liu et al., 2007; Reinisch \& Tschachler, 2005). Therefore, we hypothesized that sensory responses obtained from the fingerpad would exhibit a greater range than when the materials were assessed at other body sites. We hypothesized further that the TPT would reveal a greater affective (emotional) response at the proximal hairy skin sites than at the fingerpad.

The manner in which stimuli are delivered to a skin site is important in determining the percept elicited. Whether touch is self-directed or applied by another individual can alter perception for both sensory attributes such as size (Bolanowski, Verrillo, \& McGlone, 1999; 2004; Verrillo, Bolanowski, \& McGlone, 2003), and emotional attributes such as 'pleasantness' (Guest et al., 2009). Regarding the latter, self-directed touch can lead to diminished intensity and pleasantness of stimulation as compared with that where the stimuli are applied by another individual. This attenuation may be driven by efferent information available to the toucher's nervous system during self-touch, the goal of attenuation being to increase the perceiver's sensitivity to sensory input arising external to one's self ('forward modeling'; see Blakemore, Wolpert, \& Frith, 2000; Weiskrantz, Elliot, \& Darlington, 1971; Wolpert, 1997). Therefore, we hypothesized that the TPT would reveal lower ratings of emotional and sensory aspects of touch perception when stimuli were self-applied versus experimenter-applied in Experiment III.

\section{Methods}

\section{Participants}

Forty females (age range 18-60 years, mean 25 years,) took part in the experiment, none of whom took part in either of the first two experiments. Reimbursement was paid at a rate of $\$ 10 / \mathrm{h}$ and approximately $2 \mathrm{~h}$ of time for each participant was required. The study was approved on ethical and safety grounds by the University of North Carolina Biomedical Institutional Review Board (IRB).

\section{Apparatus}

Materials were applied to the skin using a device ('applicator') that allowed constant normal force to be delivered (Fig. 4). The device consisted of a central block of metal through which a pair of metal rods ran within lowfriction bushings. Attached to one end of the rod-pair was a curved plastic endpiece over which materials could be affixed. At the other end of the rod-pair was a weight that determined the force with which the material would be pressed against the skin. To maintain the chosen force $(0.23 \mathrm{~N})$ the central metal block was not allowed to reach the end of its travel at either end of the rods.

Five different stimulus materials were selected for study, namely a polyester with a 'silky' finish, a polyester with a more textured finish, unpowdered latex, cotton T-shirt material and hessian. These materials were chosen because they are representative of a wide range of textures, while being appropriate stimuli to deliver to a range of body sites, and flexible enough to mount easily onto the applicator.

\section{Design}

As a material was moved across a test site, the degree to which each of the attributes was descriptive of the experience was obtained from the participant using a fivepoint category scale - the touch perception task (TPT). The categories were; "none (not descriptive)", "slightly descriptive", "moderately descriptive", "highly descriptive" and "very highly descriptive".

The five materials were delivered to four body sites along the upper limb, namely the index fingerpad, volar forearm, fossa of the axilla (the annulus surrounding the 
Fig. 4 Stimulus applicator. The width of the (plastic) mounting point for the fabric was $12 \mathrm{~mm}$; the device is drawn to scale

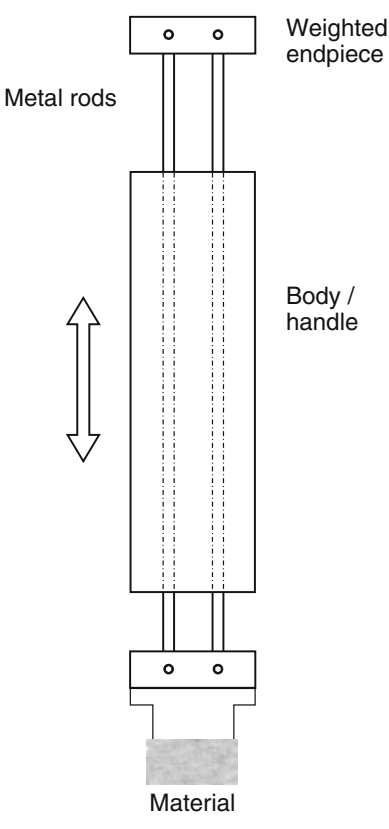

hairy central part of the underarm) and the vault of the axilla (the central, hairy portion of the underarm). The combination of body site and material was chosen randomly without replacement for each trial, until all combinations had been tested in the session. Application of stimuli was by one of three modes. The first two modes consisted of either the experimenter applying materials to the participant (E-applied condition) or the participant applying materials to her own body (S-applied condition), in each case the delivery being effected via the handheld material applicator. The third mode of delivery consisted of the participant applying materials to her own body using the index fingerpad to apply the material as opposed to the applicator (S-finger). In this delivery mode, the stimulus material was closely wrapped around the participant's fingerpad and taped together behind the finger. For selfapplications, the participant held the applicator in their dominant hand, or explored using the fingertip of that hand. The different modes of delivery were presented in separate blocks of trials. All participants experienced E-applied and S-applied modes of delivery, and 21 of the 40 participants took part in the S-finger mode. All data were collected by one female experimenter (A.M.), a clinical neurologist.

\section{Procedure}

Participants were instructed to arrive for the experiment with their armpits easily accessible, and having being shaved the previous day, with no products applied to the underarm. The shaving method was not standardized; participants were allowed to use their customary procedure.

On arrival, the participant was seated comfortably in a dental chair, shown the material applicator, and instructed how to use the device. During the instructions, a polyester material that was not used in the experiment proper was mounted on the applicator and used as an example stimulus. Stimuli were applied to each site at a rate of approximately $2 \mathrm{cms}^{-1}$. A total of $24 \mathrm{~cm}$ of skin was traversed during stimulation of forearm and both underarm sites, consisting of four back-and-forth traverses of $6 \mathrm{~cm}$. In the case of the fingerpad, $12 \mathrm{~cm}$ of skin was traversed, as six traverses of $2 \mathrm{~cm}$. Opacified welder's goggles were worn during stimulation, and removed thereafter so that the participant could mark her responses to the stimulus on the TPT, using paper and pencil. Immediately after stimulus delivery, each of the 40 TPT attributes was rated before the next stimulus was delivered.

\section{Statistical analysis}

Scores for the sensory and emotional attributes consisted of integers in the range 0 to 4 . MDS spaces were produced for Experiment III using correlations among the sensory and among the emotional scores to form dissimilarity measures. These spaces were then compared with those found in Experiment II.

Subsequently, the sensory and emotional word scores were submitted separately to factor analyses, consistent with research in the field of oral texture perception (Gámbaro et al., 2002), to determine what groups of attributes formed coherent, independent subsets (i.e., factors). SAS PROC FACTOR was used, and oblique (promax) and orthogonal (varimax) rotations were considered. To ascertain whether an omnibus factor analysis was valid, or whether different factor structures were present for subsets of the data, a separate analysis was carried out for each combination of body site and mode of touch. Further, an additional analysis was carried out using just the 21 participants with a complete dataset. In each of these analyses, similar results were obtained as in the omnibus analysis. Therefore, only the omnibus analysis is reported here. Sensory and emotional factor scores, obtained from the factor analysis via regression, were used in separate material $\times$ body site $\times$ mode of touch mixed-model (random effects) ANOVAs. Finally, to determine any relationships between sensory and emotional factors, mixed-model regression was used.

\section{Results}

Sensory words

Comparison of experiments II and III

Plots of MDS scores for the equivalent dimensions in Experiments II and III (Fig. 5) show that the perceptual 

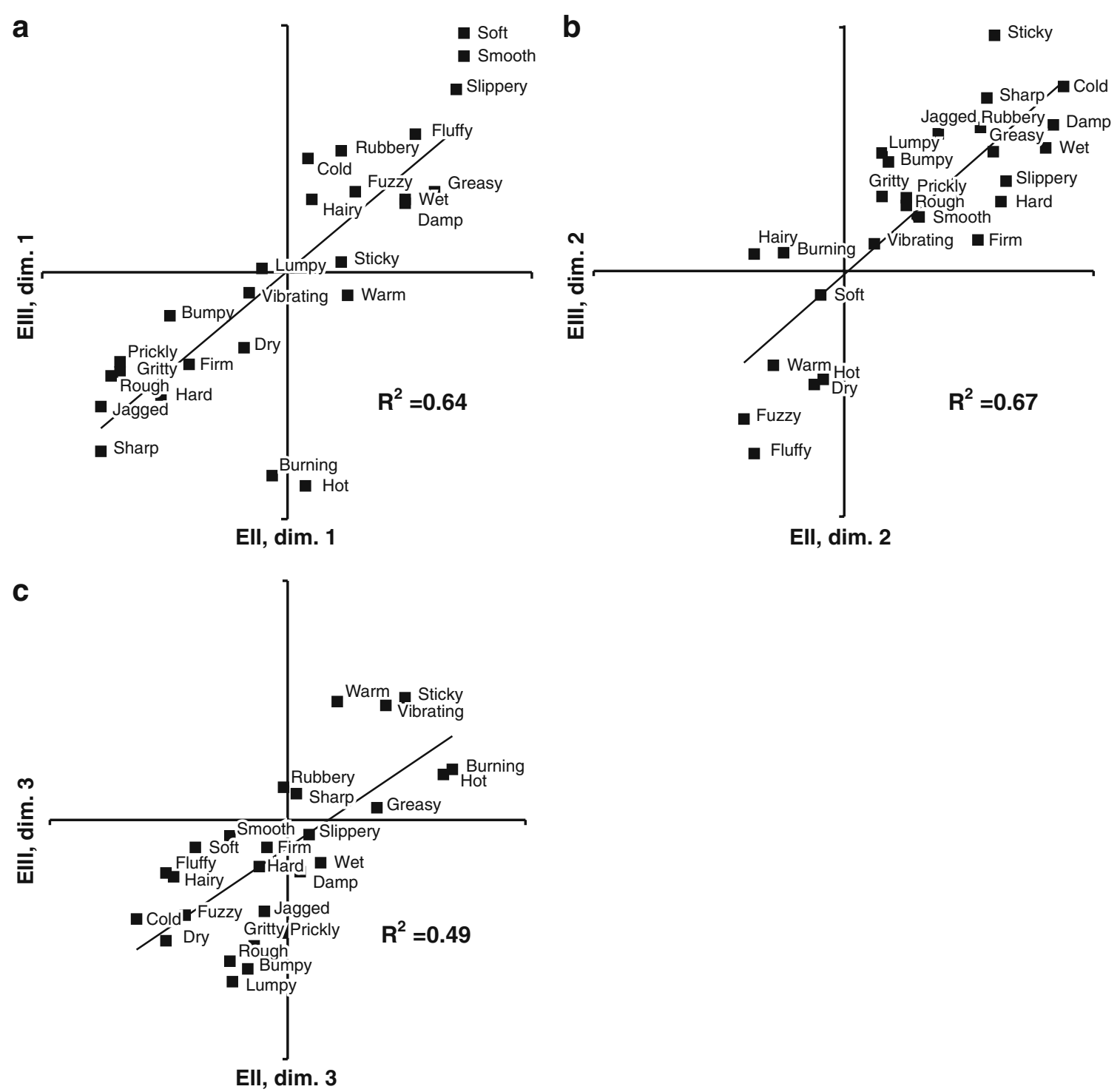

Fig. 5 MDS scores for sensory words, as obtained from the Experiment II (ordinate) and Experiment III (abscissa) data, plotted for the corresponding dimensions a-d

spaces for the two experiments were comparable. The first two dimensions were very similar. Furthermore, after exclusion of hot and burning outliers the $r^{2}$ value shown in Fig. 5a increased from 0.64 to 0.84 . The third dimension agreed less well between Experiments. Although this dimension in Experiment III could conceivably be labeled Hot-Cold, a better label would appear to be related to textural or featural surface qualities.

\section{Factor analysis}

From the 26 sensory words, four factors were extracted. After oblique rotation, the greatest correlation magnitude between a pair of factors was 0.32 , and most correlations were modest
$(<0.1)$, therefore orthogonal (varimax) rotation was considered acceptable (Tabachnick \& Fidell, 2007). Factor loadings are shown in Table 3, presented in order of loading magnitude. Four of the words did not load highly, defined as a loading of less than 0.32 on any of the factors. This was the case for hairy, sticky, vibrating and warm. The Table also shows the variance and covariance encompassed in each factor, and a descriptive label given to each factor based on inspection of the loadings. Note that with each of the 26 words contributing a single unit of variance, the factors accounted for the variance within at best 3.7 (factor 1) and at worst 1.3 (factor 4) attributes. Overall, the results of the factor analysis of the sensory attributes indicate an adequate, if not exceptional solution. 
Table 3 Factors extracted from the scores for sensory words, a descriptive label for each factor, the proportion of variance accounted for by the factor, the proportion of covariance accounted for by the factor, and loadings in order of increasing magnitude. The words hairy, sticky, vibrating and warm did not load highly on any factor (loading <.32)

\begin{tabular}{lllll}
\hline $\begin{array}{l}\text { Factor } \\
\text { Name }\end{array}$ & $\begin{array}{l}\text { Factor 1 } \\
\text { Roughness }\end{array}$ & $\begin{array}{l}\text { Factor } 2 \\
\text { Slip }\end{array}$ & $\begin{array}{l}\text { Factor } 3 \\
\text { Firmness }\end{array}$ & $\begin{array}{l}\text { Factor } 4 \\
\text { Pile }\end{array}$ \\
\hline \%variance & 14.0 & 8.8 & 6.8 & 5.0 \\
\%covariance & 39.6 & 27.1 & 19.1 & 14.2 \\
Loadings & Rough .73 & Wet .70 & Hard .61 & Fuzzy .66 \\
& Smooth -.71 & Damp .69 & Firm .60 & Fluffy .63 \\
& Bumpy .69 & Greasy .64 & Sharp .41 & Dry .32 \\
& Prickly .67 & Cold .59 & Hot .38 & \\
& Soft -.59 & Slippery .53 & Burning .37 & \\
& Lumpy .54 & Rubbery .41 & & \\
& Gritty .53 & & & \\
& Jagged .51 & & & \\
\hline
\end{tabular}

\section{Effects of body site}

Figure 6 illustrates that scores for the different materials varied among sites for Roughness $\left(F_{12,1,921}=6.26\right.$, $p<.0001)$, Firmness $\left(F_{12,1,921}=2.57, p=.0022\right)$ and Pile $\left(F_{12,1,921}=2.11, p=.0137\right)$. In contrast, Slip scores were not influenced by body site at all. As hypothesized, the greatest response range was seen for the finger for all three sensory factors plotted. An additional observation of interest is that the seldom-studied underarm sites garnered relatively large Roughness and Firmness scores for four out of the five materials; Hessian was the exception to this pattern for Roughness, latex the exception for Firmness. In contrast, Pile scores varied little among materials for the underarm sites.

It is additionally clear from Fig. 6 that the materials differed in their sensory properties as one would expect given their physical attributes (Slip scores are not depicted in Fig. 6, but also varied by material, $F_{4,1,921}=129.7, p<$ .0001). This is especially clear for Roughness, where the Hessian sample was perceived as roughest and the latex sample as smoothest, providing some measure of face validity for sensory factor 1 .

\section{Effects of mode of touch}

As shown in Fig. 7, scores for the different materials varied among modes of touch for Roughness $\left(F_{8,1,921}=7.51\right.$, $p<.0001)$, Slip $\left(F_{8,1,921}=2.63, p=.0072\right)$ and Firmness $\left(F_{8,1,921}=2.54, p=.0095\right)$. Consistent with the forward modeling hypothesis, when the indenting force was controlled (i.e., the applicator was used), stimulus application by the experimenter (E-applied) led to slightly greater Slip and far greater Firmness than stimulus application by the participant to their own body $(p<.05)$. Pile scores varied according to the mode of touch, in the same manner for each material $\left(F_{2,1,921}=11.96, p<.0001\right)$, and again consistent with the forward modeling hypothesis: greater scores were seen for E-applied (mean $=0.05$ ) than $\mathrm{S}$ - applied (mean $=-0.09$ ) conditions. However, with respect to Roughness, no consistent patterns were observed regarding the E-applied versus S-applied conditions.

Unlike the conditions that used the force-controlled applicator, factor scores for the S-finger condition did not exhibit a clear or consistent pattern, except for Roughness where S-finger led to a relatively wide range of Roughness scores (Fig. 7a).

\section{Emotional attributes}

\section{Comparison of experiments II and III}

As for the comparison of the sensory words, plots of emotional word MDS scores for the equivalent dimensions in Experiments II and III (Fig. 8) indicate that the perceptual spaces for the two experiments were broadly similar. The agreement between emotional MDS solutions between experiments was perhaps less compelling than the agreement in sensory solutions (compare Fig. 8 with Fig. 5). In particular, the correlation in Fig. 8a appears primarily driven by outlier scores for discomfort and irritating.

\section{Factor analysis}

From the 14 emotional words, two factors were extracted. A correlation of -0.57 between these factors after oblique (promax) rotation necessitated accepting the obliquely rotated solution (Tabachnick \& Fidell, 2007). Table 4 presents a summary of the factor analysis, from which it can be seen that the first factor describes Comfortrelated aspects of the emotional response to stimulation, whereas the second factor describes more Arousal-related responses.

\section{Emotional factors}

The emotional factor scores were analyzed via a mixedmodel ANOVA, following the same general approach as 

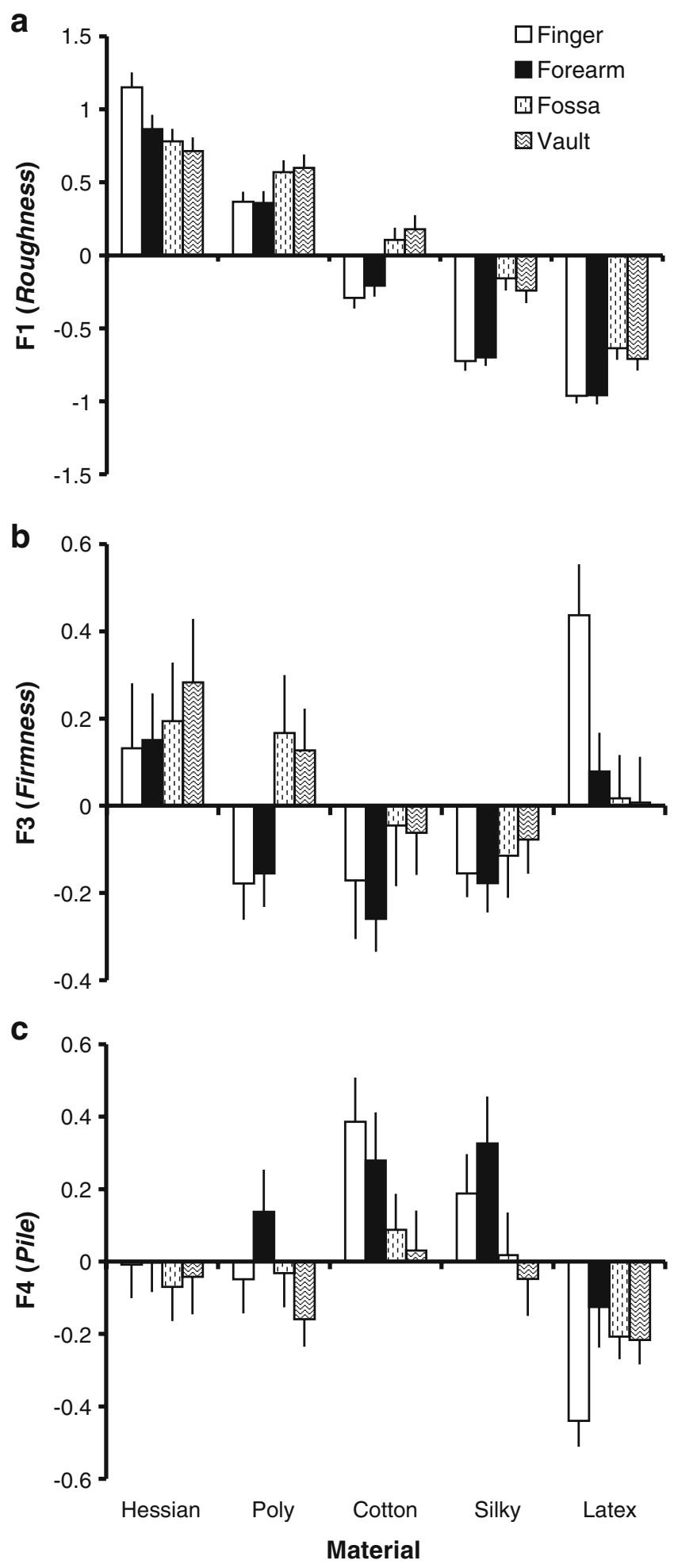

Fig. 6 Mean sensory factor scores by site and material for a factor 1 (Roughness), b factor 3 (Firmness) and c factor 4 (Pile). Error bars $+1 \mathrm{SE}$ for the sensory factors. However, because of the high correlation between the two emotional factors, a RoyBargmann stepdown analysis was used (Finch, 2007; Roy \& Bargmann, 1958; Tabachnick \& Fidell, 2007). This consisted of an initial ANOVA testing the more important of the two emotional factors in terms of variance explained, namely Comfort, followed by an ANOVA testing the dependent variable Arousal with Comfort included as a covariate.

\section{Body sites}

Comfort scores varied according to the combination of material and site $\left(F_{12,1,921}=5.87, p<.0001\right.$; Fig. 9a). Although the different materials were consistent in terms of their relative Comfort scores (e.g., the Hessian sample was rated low in Comfort, regardless of the site), differences among sites were pronounced for certain materials. For example, the cotton and silky materials were rated particularly low in Comfort for the underarm sites. Stimulation of the morphologically hairy skin of the forearm led to a greater Comfort response than the glabrous fingerpad, at least for the materials that received positive ratings (i.e., cotton, silky and latex), consistent with our stated hypothesis.

After adjusting for the effect of Comfort, Arousal varied according to site $\left(F_{3,1,881}=9.69, p<.0001\right)$, with the greatest Arousal observed at the forearm (mean $=0.07$ ), followed by the vault $(0.04)$, fossa $(-0.04)$ and then finger $(-0.10)$. Pairwise tests indicated that the finger differed from the vault and forearm, and the forearm differed from the fossa, This result indicates especially low Arousal was experienced from materials when they were explored using the fingertip.

\section{Mode of touch}

The mode of touch influenced Comfort scores differently for the different materials $\left(F_{8,1,921}=4.94, p<.0001\right)$, although as shown in Fig. 9b, the consistency of the effect of mode of touch for each material was more striking than any differences among materials. The only notable basis for the interaction was in the S-finger condition, which showed the lowest Comfort for Hessian, but the greatest Comfort of the three modes of touch for the silky and latex materials.

After adjusting for the effect of Comfort, Arousal scores also varied according to the mode of touch and material $\left(F_{8,1,881}=2.78, p=.005\right)$. As was the case for Comfort, the two modes of touch that used the applicator were very consistent in their relative Arousal scores; greater Arousal was observed for the E-Applied (mean = $0.01)$ than S-Applied (mean $=-0.15$ ) mode. In contrast, 

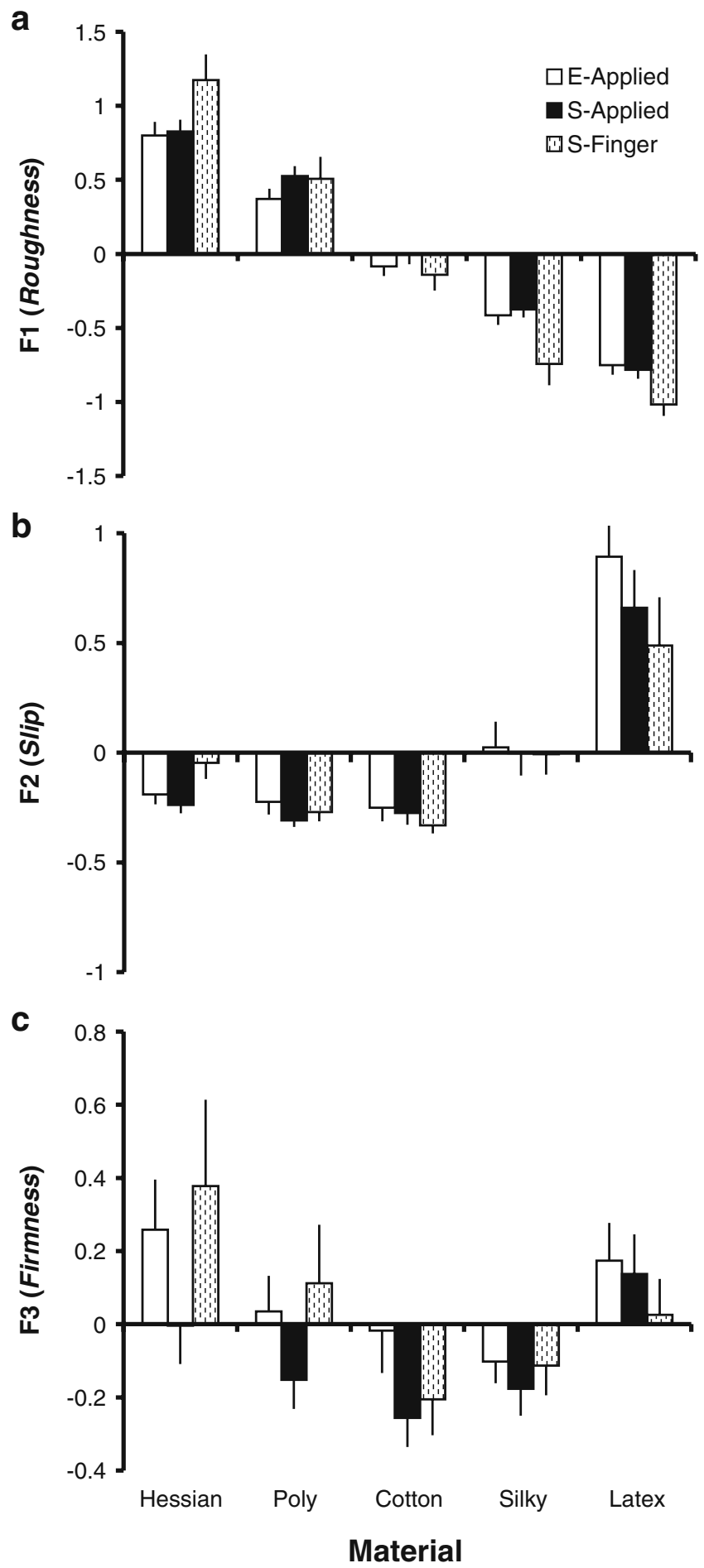

Fig. 7 Mean sensory scores by mode of touch and material for a factor 1 (Roughness), b factor 2 (Slip) and c factor 3 (Firmness)

the S-Finger condition showed scores comparable to those of the E-Applied condition, except for the latex and Hessian material, which received scores that were particularly high in magnitude (mean of 0.29 and 0.25 , respectively).
Relationships between sensory and emotional factors

Finally, to investigate possible relationships between the sensory and emotional factors two mixed-model regressions were used. The first included Comfort as the dependent variable, and each of the four sensory factors as (randomeffects) predictors. The second included Arousal as the dependent variable, and the four sensory factors and Comfort as predictors.

Comfort increased with decreasing roughness $\left(F_{1,39}=\right.$ 194.8, $p<.001$; slope $=-0.62)$, increasing slipperiness $\left(F_{1,39}=22.60, p<.001 ;\right.$ slope $\left.=0.21\right)$ and increasing pile $\left(F_{1,39}=55.4, p<.001 ;\right.$ slope $\left.=0.28\right)$. In contrast, Arousal increased with increasing roughness $\left(F_{1,39}=6.10, p=018\right.$; slope $=0.09)$, firmness $\left(F_{1,39}=32.5, p<.001 ;\right.$ slope $=$ $0.16)$ and pile $\left(F_{1,39}=4.85, p=.034\right.$; slope $\left.=0.09\right)$.

\section{General discussion}

Our results impact two important topics within tactile perception. First, the development process of the suggested touch lexicon expands our knowledge of perceptual spaces. Second, the empirical results obtained using the TPT demonstrate how sensory and affective perception varies for specific body sites and modes of touch, and addresses how sensory and affective aspects are related in the perception of textured materials. These two topics are addressed below.

\section{Perceptual structure of sensory and emotional touch}

Comparing the results of the available studies in the literature (Table 5), there is some agreement on the structure of sensory tactile perception space. Most consistently, the primary dimension is invariably analogous to Rough-Smooth. The higher order dimensions, and their level of description, vary somewhat depending on the paradigm, stimuli and mode of exploration of the stimuli. For example, Experiment II investigated the pure semantic relationships between sensory words, and in consequence, returned a very general perceptual space, covering such fundamental qualities as roughness, temperature and wetness. Indeed, this space is perhaps the closest of those reported to date to an archetypal or 'global' perceptual space. Note that the words from which the global space of Experiment II was produced were quite capable of forming a more specific perceptual space, as seen in Experiment III. In this case, the words that were irrelevant to the roomtemperature textiles that formed the stimuli of Experiment III were essentially unused (e.g., hot and burning). In another example of this specificity, studies that have 


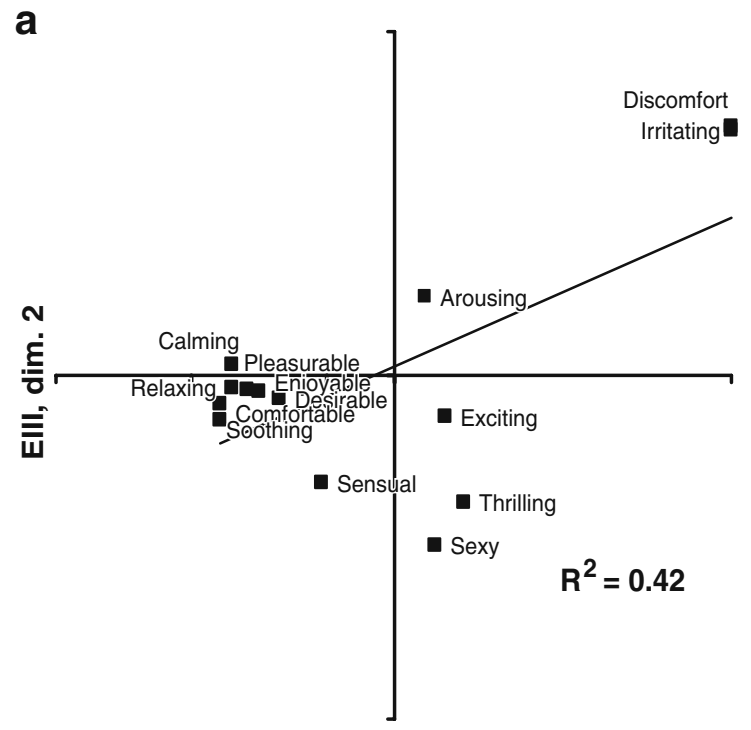

Ell, dim. 1

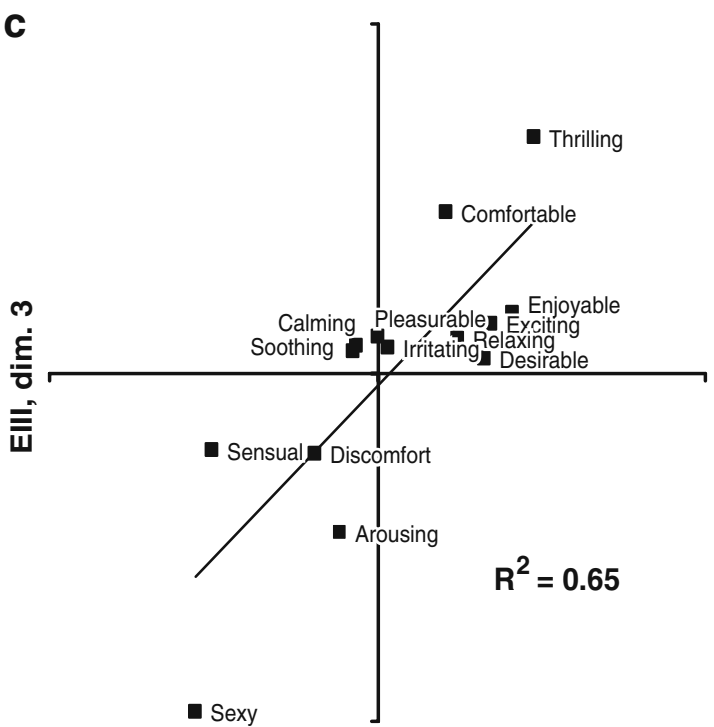

Ell, dim. 3

Fig. 8 MDS scores for emotional words, as obtained from the Experiment II (ordinate) and Experiment III (abscissa) data, plotted for the three corresponding dimensions a-c. Note that Experiment II

involved fabrics that are handled rather than just touched, report a Thin-Thick dimension (Na \& Kim, 2001; Soufflet et al., 2004). That is, the emergence of Thin-Thick appears to require haptic manipulation of, rather than purely tactile interactions with, stimuli.

In the light of the above observations, we propose a criterion for a suitable touch lexicon whereby the words of such a lexicon should be capable of producing a global perceptual space (as in Experiment II), but also of producing specific perceptual spaces, depending on the precise task-related percepts those words must describe. The words chosen for the TPT of Experiment III pass this

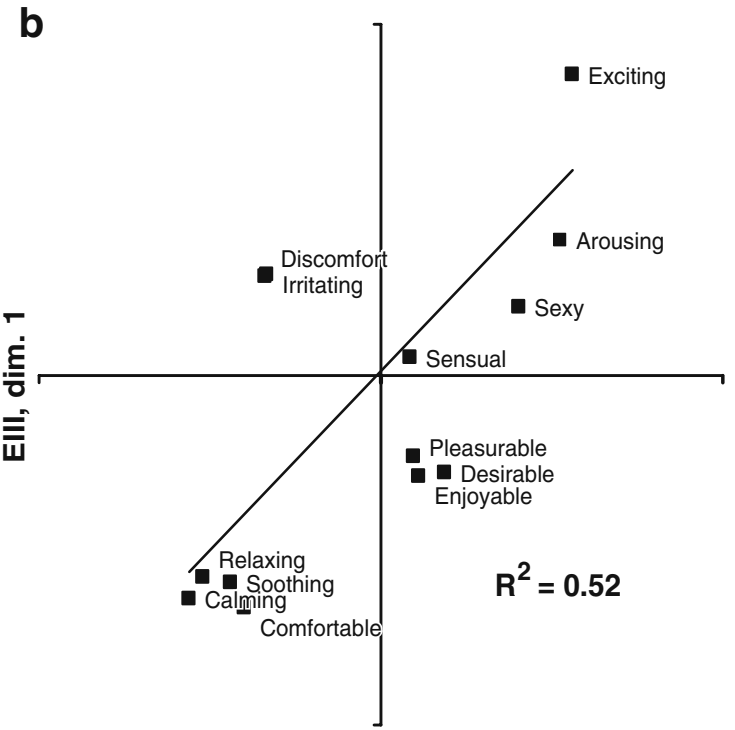

Ell, dim. 2 dimension 1 was equivalent to Experiment III dimension 2, whereas Experiment II dimension 2 was equivalent to Experiment III dimension 1

test, although this does not imply that the TPT comprises a unique touch lexicon per se. Nor do we know whether the TPT words are capable of being used to describe the applicable perceptual dimensions for every conceivable task and stimulus set.

In contrast to the sensory dimensions, prior data are unavailable that explicitly detail the emotional dimensions of tactile perception. However, the emotional dimensions of the semantic-perceptual space reported here may be compared with semantic-perceptual spaces pertaining to more general aspects of human emotional experience. Primary among these is a three-factor structure (Osgood, 
Table 4 Factors extracted from the emotional words, a descriptive label for each factor, the proportion of variance accounted for by the factor, the proportion of covariance accounted for by the factor, and loadings in order of increasing magnitude. Variances and covariances are given prior to rotation and are thus only approximate indicators of variance and covariance after oblique rotation. Loadings are those from the pattern matrix. Some attributes loaded highly on both factors and thus appear in both factor loading lists

\begin{tabular}{lll}
\hline $\begin{array}{l}\text { Factor } \\
\text { Name }\end{array}$ & $\begin{array}{l}\text { Factor 1 } \\
\text { Comfort }\end{array}$ & $\begin{array}{l}\text { Factor 2 } \\
\text { Arousal }\end{array}$ \\
\hline $\begin{array}{l}\text { \%variance } \\
\text { \%covariance }\end{array}$ & 51.1 & 10.6 \\
Loadings & 82.8 & 17.2 \\
& Irritating -.80 & Exciting .84 \\
& Comfortable .76 & Arousing .76 \\
& Discomfort -.76 & Thrilling .74 \\
Relaxing .72 & Sensual .68 \\
Calming .69 & Sexy .59 \\
& Soothing .67 & Pleasurable .55 \\
Enjoyable .53 & Desirable .51 \\
& Desirable .48 & Enjoyable .47 \\
& Pleasurable .46 & \\
\hline
\end{tabular}

1952; Osgood \& Suci, 1955; Russell \& Mehrabian, 1977; Russell \& Steiger, 1982) that suggests any emotional response is embodied as having certain amounts of three independent qualities, namely Pleasure, Arousal and Dominance. Comparing the results from Experiment II with this prior work, there are clear similarities between Pleasure and (tactile) Discomfort-Comfort, and between Arousal and the emotional dimension we gave the same label. Dominance and Sensual Quality are less obviously analogous. Dominance has failed to clearly emerge in other sensory perception research. For example, odor perception space has a primary hedonic dimension corresponding to Pleasure or Erogeneous quality (Zarzo \& Stanton, 2009) and arguably a secondary Arousal (or Active quality) dimension, but no clear analog of a Dominance dimension.

Although the Experiment II results for the emotional words are in agreement with the broader emotional perception literature, the Experiment III results are not so obviously concordant. In Experiment III as in Experiment II, Dominance failed to emerge, although in Experiment III no tertiary factor was extracted at all. If the tactile stimuli of Experiment III simply did not differ in their Dominance (e.g., Foxall \& Greenley, 1998), this could explain the lack of emergence. It is also possible that Dominance is only of consequence in interactions between, or assessments of, other humans (e.g., perception of body posture, Mehrabian, 1970; perception of facial expression, Osgood, 1966). In contrast, it seems likely that Pleasure and Arousal are indeed universal dimensions of any emotionally based judgment.
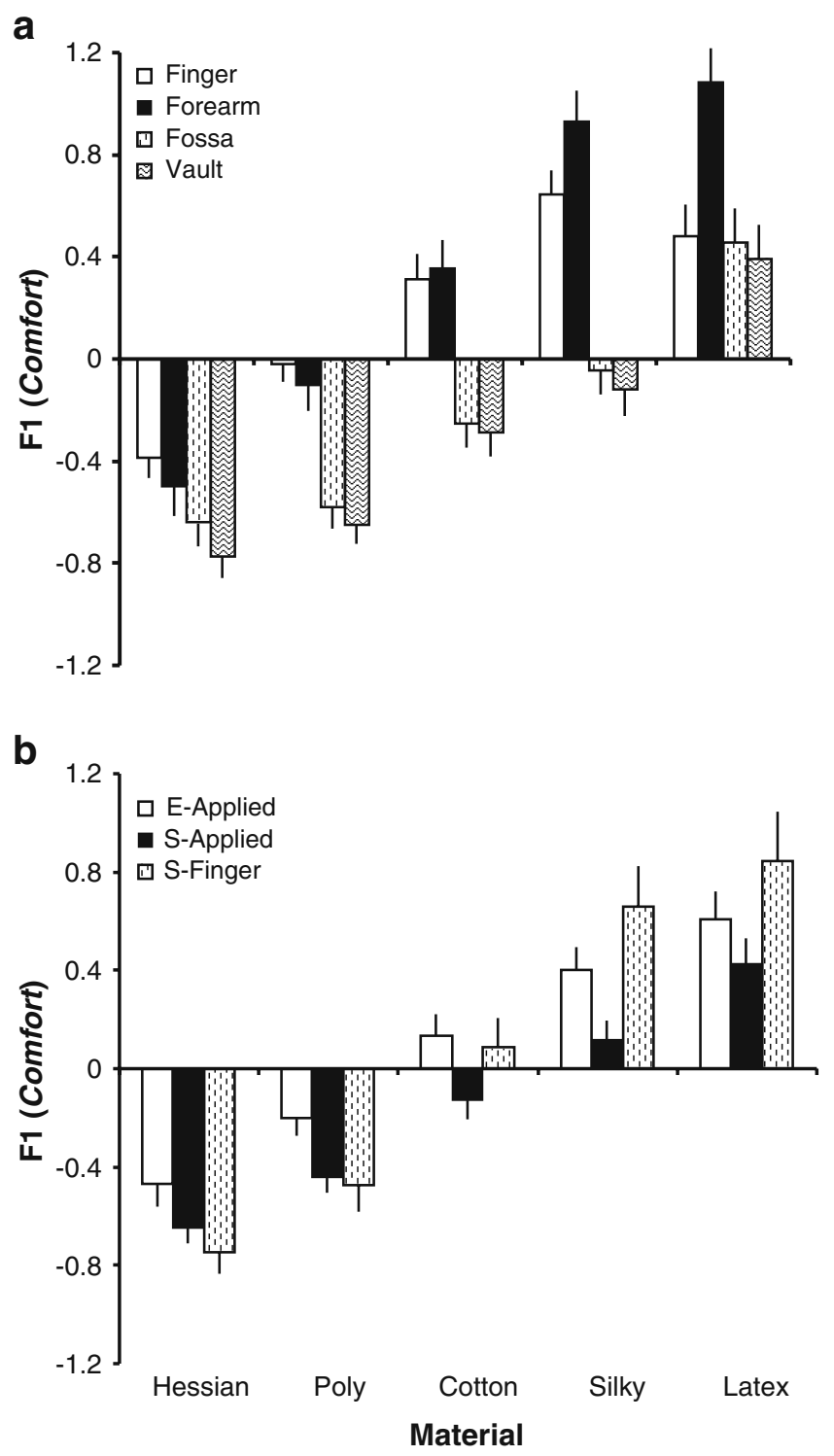

Fig. 9 Mean emotional factor 1 (Comfort) scores for a site and material, b mode and material

A potentially more critical issue for the emotional attributes of the TPT is that the factor analysis of Experiment III's data suggested that an orthogonal solution was not statistically justifiable, whereas Pleasure, Arousal and Dominance are generally considered orthogonal. The non-orthogonal solution also complicated the interpretation of the factors because individual attributes loaded highly on more than one factor (for example, see the attribute pleasurable in Table 4), an inherent property of oblique factor rotation. Consequently, the descriptive value of the labels chosen for each of the factors is reduced, and individual factor scores are more difficult to interpret than in an orthogonal solution.

Although the correlated factor solution appears at odds with the literature, we note that some prior research has 
Table 5 Comparison of the sensory perceptual spaces suggested in current and prior research. Question marks denote that the dimension label is tentative, either because the researchers did not give a label, or because they provided a label that they explicitly stated as tentative

\begin{tabular}{|c|c|c|c|c|}
\hline \multirow[b]{2}{*}{ Study } & \multirow[b]{2}{*}{ Stimuli } & \multicolumn{3}{|l|}{ Dimension } \\
\hline & & 1 & 2 & 3 \\
\hline Current, Experiment II & 33 sensory words & Rough-smooth & Wet-dry & Hot-cold \\
\hline Current, Experiment III & 5 textured stimuli & Rough-smooth & Wet -dry? & Texture? \\
\hline Bergmann et al., 2006 & 124 diverse materials & Soft-hard? & Rough-smooth? & Featural regularity? \\
\hline Soufflet et al., 2004 & 26 fabrics & Soft-harsh & Thin-thick & Supple-stiff \\
\hline Picard et al., 2003 & 24 car seat materials & Soft-harsh & Thin-thick & Relief \\
\hline Hollins et al., 2000 & 17 diverse materials & Rough-smooth & Soft-hard & Sticky-slippery? \\
\hline Hollins et al., 1993 & 17 diverse materials & Rough-smooth & Hard--soft & Elasticity? \\
\hline
\end{tabular}

found relationships between Pleasure, Arousal and Dominance, but investigators have typically considered the magnitude of the relationships small enough that they could be ignored. For example, Russell and Mehrabian (1977) found a correlation of 0.4 between response scales for Pleasure and Dominance (see also Carroll, Yik, Russell, \& Barrett, 1999; Mehrabian \& Russell, 1974). Further, a distinction must be made between the emotional dimensions themselves, and the words that may be used to describe those dimensions. The existence of orthogonal dimensions does not imply that individual emotional descriptors are descriptive of one dimension only. For example, Shaver, Schwartz, Kirson, and O'Connor (1987) showed that emotion words clustered into six emotional categories (Love, Joy, Surprise, Anger, Sadness and Fear), with the words that formed each of these categories being relatively widely distributed within a two-dimensional MDS space. For example, words that were all part of the emotional category Anger nevertheless varied considerably in Evaluation and Intensity, the axis labels chosen by the researchers. As such, given a suitable experiment, one would be unsurprised if a factor analysis produced factors corresponding to these six emotional categories, with some degree of correlation among the factors. Indeed, earlier work by Purcell (1982) provides empirical evidence that the multidimensional (MDS-derived) structure of emotion, and the factor analytic structure of emotion are not precisely analogous: in Purcell's study, the factors did not simply correspond to the cardinal axes of the multidimensional space.

In summary, these observations suggest that the correlated emotional factors of Experiment III are not entirely inconsistent with prior research, although the magnitude of the correlation is larger than one would typically expect. One possible reason for the high correlation would be if Comfort and Arousal are highly correlated for textured materials in particular. Were the TPT used to investigate other stimuli, or a wider range of stimuli, a weaker relationship might be found. Investigating this possibility warrants further work. Such work is necessary before concluding that the emotional attributes of the TPT are in some sense optimal.

\section{The Tactile Perception Task (TPT) in use}

Our results on the use of the Tactile Perception Task (TPT) to assess the perception of textured stimuli moved over the upper limb suggest that it is an appropriate tool that can provide valuable information about both the sensory and emotional aspects of touch.

\section{Effects of body site}

As hypothesized, the TPT revealed higher emotional (Comfort and Arousal) scores at the forearm than the fingerpad, consistent with prior work from our laboratory (Essick et al., 2010; Guest et al., 2009). Such a result is further consistent with a hypothesis that low-threshold Ctactile (CT) mechanoreceptors are important in affective touch (Liu et al., 2007; Löken et al., 2009; McGlone et al., 2007; Reinisch \& Tschachler, 2005; Vallbo et al., 1999; Vallbo et al., 1993; Wessberg et al., 2003), given that hairy skin (e.g., of the forearm) is innervated by such fibers, but glabrous skin (e.g., of the fingerpad) is not (Liu et al., 2007; Reinisch \& Tschachler, 2005). However, stimulation of the glabrous fingerpad led to a greater emotional response than stimulation of either of the axillary sites, which suggests that the presence of CT afferents per se is not sufficient for stimulation of that site to elicit an especially high affective response. However, this suggestion must remain tentative given that the presence and density of CT mechanoreceptors in the fossa and vault have not been explicitly confirmed and enumerated. In addition to innervation differences, differences in the roles of our various body sites in interacting with the 
world may be important. For example, the forearm commonly receives stimulation, through contact with clothing or during interpersonal touch, but is not typically used to actively explore surfaces, unlike the fingertip (see Bolanowski et al., 2004).

Skin morphology differences (Bjerring, 1985; Southwood, 1955), leading to mechanical differences in the response of the skin to stimulation, might also underlie differences in discriminative and affective touch over the body surface. For example, the skin of the vault in females is significantly thicker than that of the fossa, perhaps as a consequence of the skin's response to frequent shaving of the vault (Turner, Moore, Marti, Paterson, \& James, 2007). Additionally, the process of shaving the vault may lead to increased sensitivity to rough or harsh stimuli moved over that region. Indeed, we found some evidence that stimuli moved over the vault were less comfortable and more arousing than those moved across the fossa. However, we found no strong evidence that any of the sensory (i.e., Roughness, Slip, Firmness and Pile) responses varied consistently between these two sites.

\section{Mode of touch}

The TPT confirmed that precisely how a material is moved across an individual's body is very important in the perception of that material. In particular, when the forcecontrolled applicator was used, greater Slip, Firmness, Pile and mean emotional factor scores were obtained when the experimenter applied the materials to the participant, as opposed to when the participant applied the materials to their own body. The lower scores seen for self- versus experimenter-derived touch when using the applicator are consistent with sensory attenuation as suggested by the forward modeling hypothesis (Blakemore et al., 2000; Weiskrantz et al., 1971; Wolpert, 1997).

More complex patterns of perception were seen for selftouch using the fingerpad, with no clear correspondence with either of the two conditions that used the forcecontrolled stimulus applicator. The complexity may have been mediated by the lack of control of the force with which stimuli were applied, by the tactile and proprioceptive input available at the moving fingerpad in this condition alone, and by the generally high sensitivity of this body site.

The emotional response to the different modes of touch may have been influenced by the social aspects of the stimulus presentation in addition to the self-generated forward modeling. That is, application of a stimulus by one individual to the skin of another represents social touch at some level, and is thus open to a variety of concomitants of social touch (Fisher, Rytting, \& Heslin, 1976; Guest et al., 2009; Hertenstein, Keltner, App, Bulleit, \& Jaskolka, 2006; Wilhelm, Kochar, Roth, \& Gross, 2001). Overall, we found that emotional factor scores tended to be greater when touched by another, and though a sensory-based explanation for this appears likely, as discussed above, the possibility that higher-order cognitive processes were at play cannot be excluded.

The relationship between sensory and emotional percepts

Relationships have been found in prior studies between pleasantness and perceptual qualities such as harshness, softness and roughness (Essick et al., 1999; Essick et al., 2010; Major, 1895; Ripin \& Lazarsfeld, 1937), and between pleasantness and explicit perceptual ratings of physical stimulus characteristics such as friction (Cardello et al., 2003). However, the interpretation of prior MDS studies is complicated by the possibility that participants sort or rate stimuli along hedonic as well as sensory stimulus attributes. In some studies, the primary MDS axis has indeed been found to correlate highly with hedonic as well as sensory attributes (Picard et al., 2003; Soufflet et al., 2004). However, one cannot know whether this correlation occurred because stimuli were sorted according to hedonic and sensory aspects of the stimuli (see Clark \& Lawless, 1994) or whether the sorting took into account sensory aspects only, with the correlation being a consequence of, for example, rough stimuli feeling less pleasant. These problems were avoided in the current study by allowing participants to explicitly rate emotional and sensory attributes of the stimulus set separately. Consequently, we found that greater Comfort was associated with reducing roughness, increasing slipperiness and pile. Greater Arousal was associated with increasing Roughness, Firmness and Pile.

\section{Conclusions}

The current study demonstrates that a touch lexicon, generated according to established principles from related fields of psychometrics, has an orderly and interpretable structure. A derived TPT is sensitive as evidenced by its capability of confirming perceptual and affective differences according to the mode of touch, body site, innervation differences, and material moved across the skin surface. The TPT has advantages in that it allows a more fine-grained classification of the sensory and emotional experience of touch than traditional psychophysical tools, while remaining simple to use, by virtue of it being based on the naturally-occurring use of language in female speakers of American English.

Acknowledgements In memory of Stanley "Sandy" J. Bolanowski and Ronald T. Verrillo for their lifelong contributions to sensory research and for inspiring and instigating the present work. 


\section{References}

Bergmann Tiest, W. M., \& Kappers, A. M. I. (2006). Analysis of haptic perception of materials by multidimensional scaling and physical measurements of roughness and compressibility. Acta Psychologica, 121, 1-20.

Bhushan, N., Rao, A. R., \& Lohse, G. L. (1997). The texture lexicon: Understanding the categorization of visual texture terms and their relationship to texture images. Cognitive Science, 21, 219-246.

Bjerring, P. (1985). Skin elasticity measured by dynamic admittance a new technique for mechanical measurements in patients with scleroderma. Acta Dermato-Venereologica, 120 Suppl., 83-87.

Blakemore, S.-J., Wolpert, D., \& Frith, C. (2000). Why can't you tickle yourself? NeuroReport, 11, R11-R16.

Bolanowski, S. J., Verrillo, R. T., \& McGlone, F. P. (1999). Passive, active, and intra-active (self) touch. Somatosensory \& Motor Research, 16, 304-311.

Bolanowski, S. J., Verrillo, R. T., \& McGlone, F. P. (2004). Passive, active and intra-active (self) touch. Behavioural Brain Research, $148,41-45$.

British National Corpus. (2007). Retrieved 22nd May, 2008, from http://www.natcorp.ox.ac.uk/

Cardello, A. V., Winterhalter, C., \& Schutz, H. G. (2003). Predicting the handle and comfort of military clothing fabrics from sensory and instrumental data: Development and application of new psychophysical methods. Textile Research Journal, 73, 221-237.

Carroll, J. M., Yik, M. S. M., Russell, J. A., \& Barrett, L. F. (1999). On the psychometric principles of affect. Review of General Psychology, 3, 14-22.

Cattell, R. B. (1978). The scientific use of factor analysis in behavioral and life sciences. New York: Plenum.

Clark, C. C., \& Lawless, H. T. (1994). Limiting response alternatives time-intensity scaling: An examination of the halo-dumping effect. Chemical Senses, 19, 583-594.

Essick, G. K., James, A., \& McGlone, F. P. (1999). Psychophysical assessment of the affective components of non-painful touch. NeuroReport, 10, 2083-2087.

Essick, G. K., McGlone, F. P., Dancer, C., Fabricant, D., Ragin, Y., Phillips, N., et al. (2010). Quantitative assessment of pleasant touch. Neuroscience and Biobehavioral Reviews, 34, 192-203.

Finch, W. H. (2007). Performance of the Roy-Bargmann stepdown procedure as a follow up to a significant MANOVA. Multiple Linear Regression Viewpoints, 33, 12-22.

Fisher, J. D., Rytting, M., \& Heslin, R. (1976). Hands touching hands: Affective and evaluative effects of an interpersonal touch. Sociometry, 39, 416-421.

Foxall, G., \& Greenley, G. (1998). The affective structure of consumer situations. Environment and Behavior, 30, 781-798.

Gámbaro, A., Varela, P., Giménez, A., Aldrovandi, A., Fiszman, S. M., \& Hough, G. (2002). Textural quality of white pan bread by sensory and instrumental measurements. Journal of Texture Studies, 33, 401-413.

Gescheider, G. A., Bolanowski, S. J., Greenfield, T. C., \& Brunette, K. E. (2005). Perception of the tactile texture of raised-dot patterns: A multidimensional analysis. Somatosensory \& Motor Research, 22, 127-140.

Guest, S., Essick, G. K., Dessirier, J. M., Blot, K., Lopetcharat, K., \& McGlone, F. P. (2009). Sensory and affective judgments of skin during inter- and intrapersonal touch. Acta Psychologica, 130, 115-126.

Hertenstein, M. J., Keltner, D., App, B., Bulleit, B. A., \& Jaskolka, A. R. (2006). Touch communicates distinct emotions. Emotion, 6, 528-533.

Hollins, M., Bensmaïa, S., Karlof, K., \& Young, F. (2000). Individual differences in perceptual space for tactile textures: Evidence from multidimensional scaling. Perception \& Psychophysics, 62, 1534-1544.

Hollins, M., Faldowski, R., Rao, S., \& Young, F. (1993). Perceptual dimensions of tactile surface texture: A multidimensional scaling analysis. Perception \& Psychophysics, 54, 697-705.

Klatzky, R. L., \& Lederman, S. J. (1999). Tactile roughness perception with a rigid link interposed between skin and surface. Perception \& Psychophysics, 61, 591-607.

LaMotte, R. H. (2000). Softness discrimination with a tool. Journal of Neurophysiology, 83, 1777-1786.

Lederman, S. J. (1974). Tactile roughness of grooved surfaces: The touching process and effects of macro- and microsurface structure. Perception \& Psychophysics, 16, 385-395.

Lederman, S. J., \& Klatzky, R. L. (1987). Hand movements: A window into haptic object recognition. Cognitive Psychology, 19, $342-368$.

Lederman, S. J., \& Klatzky, R. L. (1990). Haptic classification of common objects: Knowledge-driven exploration. Cognitive Psychology, 22, 421-459.

Lederman, S. J., \& Taylor, M. M. (1972). Fingertip force, surface geometry and the perception of roughness by active touch. Perception \& Psychophysics, 12, 401-408.

Liu, Q., Vrontou, S., Rice, F. L., Zylka, M. J., Dong, X., \& Anderson, D. J. (2007). Molecular genetic visualization of a rare subset of unmyelinated sensory neurons that may detect gentle touch. Nature Neuroscience, 10, 946-948.

Löken, L. S., Wessberg, J., Morrison, I., McGlone, F. P., \& Olausson, H. (2009). Coding of pleasant touch by unmyelinated afferents in humans. Nature Neuroscience, 12, 547-548.

Major, D. R. (1895). On the affective tone of simple senseimpressions. The American Journal of Psychology, 7, 57-77.

McGlone, F. P., Vallbo, Å., Olausson, H., Loken, L., \& Wessberg, J. (2007). Discriminative touch and emotional touch. Canadian Journal of Experimental Psychology, 61, 175-183.

Mehrabian, A. (1970). A semantic space for nonverbal behavor. Journal of Consulting and Clinical Psychology, 35, 248-257.

Mehrabian, A., \& Russell, J. A. (1974). An approach to environmental psychology. Cambridge: M.I.T. Press.

Melzack, R. (1975). The McGill pain questionnaire: Major properties and scoring methods. Pain, 1, 277-288.

Melzack, R. (1987). The short-form McGill Pain Questionnaire. Pain, 30, 191-197.

Na, Y., \& Kim, C. (2001). Quantifying the handle and sensibility of woven silk fabrics. Textile Research Journal, 71, 739-742.

Osgood, C. E. (1952). The nature and measurement of meaning. Psychological Bulletin, 49, 197-237.

Osgood, C. E. (1966). Dimensionality of the semantic space for communication via facial expressions. Scandinavian Journal of Psychology, 7, 1-30.

Osgood, C. E., \& Suci, G. J. (1955). Factor analysis of meaning. Journal of Experimental Psychology, 50, 325-338.

Petiot, J.-F., \& Yannou, B. (2004). Measuring consumer perceptions for a better comprehension, specification and assessment of product semantics. International Journal of Industrial Ergonomics, 33, 507-525.

Picard, D., Dacremont, C., Valentin, D., \& Giboreau, A. (2003). Perceptual dimensions of tactile textures. Acta Psychologica, $114,165-184$

Purcell, A. T. (1982). The structure of activation and emotion. Multivariate Behavioral Research, 17, 221-251.

Reinisch, C. M., \& Tschachler, E. (2005). The touch dome in human skin is supplied by different types of nerve fibers. Annals of Neurology, 58, 88-95.

Ripin, R., \& Lazarsfeld, P. F. (1937). The tactile-kinaesthetic perception of fabrics with emphasis on their relative pleasantness. The Journal of Applied Psychology, 21, 198-224. 
Roy, S. N., \& Bargmann, R. E. (1958). Tests of multiple independece and the associated confidence bounds. The Annals of Mathematical Statistics, 29, 491-503.

Russell, J. A., \& Mehrabian, A. (1977). Evidence for a three-factor theory of emotions. Journal of Research in Personality, 11, 273-294.

Russell, J. A., \& Steiger, J. H. (1982). The structure in persons' implicit taxonomy of emotions. Journal of Research in Personality, 16, 447-469.

Sathian, K., \& Zangaladze, A. (1996). Tactile spatial acuity at the human fingertip and lip: Bilateral symmetry and interdigit variability. Neurology, 46, 1464-1466.

Shaver, P., Schwartz, J., Kirson, D., \& O'Connor, C. (1987). Emotion knowledge: Further exploration of a prototype approach. Journal of Personality and Social Psychology, 52, 1061-1086.

Smith, A. M., Chapman, C. E., Deslandes, M., Langlais, J.-S., \& Thibodeau, M.-P. (2002). Role of friction and tangential force variation in the subjective scaling of tactile roughness. Experimental Brain Research, 144, 211-223.

Soufflet, I., Calonnier, M., \& Dacremont, C. (2004). A comparison between industrial experts' and novices' haptic perceptual organization: A tool to identify descriptors of the handle of fabrics. Food Quality and Preference, 15, 689-699.

Southwood, W. F. W. (1955). The thickness of the skin. Plastic and Reconstructive Surgery, 15, 423-429.

Srinivasan, M. A., \& LaMotte, R. H. (1995). Tactual discrimination of softness. Journal of Neurophysiology, 73, 88-101.

Stevenson, R. J., \& Boakes, R. A. (2003). A mnemonic theory of odor perception. Psychological Review, 110, 340-364.

Tabachnick, B. G., \& Fidell, L. S. (2007). Using multivariate statistics (5th ed.). Boston: Allyn \& Bacon.

Turner, G. A., Moore, A. E., Marti, V. P. J., Paterson, S. E., \& James, A. G. (2007). Impact of shaving and anti-perspirant use on the axillary vault. International Journal of Cosmetic Science, 29, 3138.

Vallbo, Å., Olausson, H., \& Wessberg, J. (1999). Unmyelinated afferents constitute a second system coding tactile stimuli of the human hairy skin. Journal of Neurophysiology, 81, 27532763 .

Vallbo, A., Olausson, H., Wessberg, J., \& Norrsell, U. (1993). A system of unmyelinated afferents for innocuous mechanoreception in the human skin. Brain Research, 628, 301-304.

Verrillo, R. T., Bolanowski, S. J., \& McGlone, F. P. (2003). Intra- and interactive touch on the face. Somatosensory \& Motor Research, 20, 3-11.

Weiskrantz, L., Elliot, J., \& Darlington, C. (1971). Preliminary observations on tickling oneself. Nature, 230, 598-599.

Wessberg, J., Olausson, H., Fernström, K. W., \& Vallbo, A.. (2003). Receptive field properties of unmyelinated tactile afferents in the human skin. Journal of Neurophysiology, 89, 1567-1575.

Wilhelm, F. H., Kochar, A. S., Roth, W. T., \& Gross, J. J. (2001). Social anxiety and response to touch: Incongruence betwen selfevaluative and physiological reactions. Biological Psychology, $58,181-202$.

Wolpert, D. (1997). Computational approaches to motor control. Trends in Cognitive Sciences, 1, 209-216.

Yoshida, M. (1968). Dimensions of tactile impressions. Japanese Psychological Research, 10, 123-137.

Zarzo, M., \& Stanton, D. T. (2009). Understanding the underlying dimensions in perfumers' odor perception space as a basis for developing meaningful odor maps. Attention, Perception \& Psychophysics, 71, 225-247.

Zhang, L., Helander, M. G., \& Drury, C. G. (1996). Identifying factors of comfort and discomfort in sitting. Human Factors, 38, 377389. 